\title{
Fios que Tecem o Tempo Escolar: do ritmo padrão à simultaneidade
}

\author{
Ana Sueli Teixeira de Pinho' \\ Elizeu Clementino e Souza" \\ 'Universidade Católica do Salvador (UCSal), Salvador/BA - Brasil \\ "Universidade do Estado da Bahia (UNEB), Salvador/BA - Brasil
}

RESUMO - Fios que Tecem o Tempo Escolar: do ritmo padrão à simultaneidade. Este texto tem por objetivo tecer os fios que, de modo complexo, atam e desatam, de forma silenciosa, a constituição do tempo em duas escolas com classes multisseriadas da Ilha de Maré, problematizando a ideia de ritmo padrão e apontando a simultaneidade como possibilidade para o tempo escolar. Do ponto de vista metodológico foi adotada a narrativa (auto)biográfica, e a técnica de pesquisa selecionada foi a entrevista narrativa. O estudo realizado aponta que o tempo escolar, das duas escolas pesquisadas, é convidado a reconhecer a existência e a legitimidade de outros tempos, para além do seu: o tempo da maré, o tempo do trabalho, o tempo das práticas simbólicas, o tempo livre e as temporalidades dos sujeitos.

Palavras-chave: Tempo Escolar. Ritmo Padrão. Simultaneidade. Narrativa (Auto)Biográfica.

ABSTRACT - Threads That Weave The School Time: From Standard Rhythm To Simultaneity. This text aims to weave the threads that, in a complex way, bind and unbind, silently, the constitution of time in two schools with multigrade classes of Maré Island, questioning the idea of rhythm pattern and pointing concurrency as a possibility for school time. From a methodological point of view was adopted the narrative (auto) biographical and the selected search technique was narrative interview. The study points out that the school time, the two schools surveyed, is invited to recognize the existence and legitimacy of other times, beyond their, is the time of the tide, the work time, the time of symbolic practices, free time and the temporality of the subject.

Keywords: School Time. Default Rhythm, Simultaneity. Narrative (Auto) Biographical.

Educação \& Realidade, Porto Alegre, v. 42, n. 3, p. 1183-1204, jul./set. 2017. 1183 http://dx.doi.org/10.1590/2175-623660927 


\section{Introdução}

O que pretendemos neste texto ${ }^{1}$ é problematizar a forma como o tempo escolar foi concebido historicamente, fazendo emergir as tensões e contradições que tal lógica tentou ocultar ou naturalizar. A intenção é costurar as relações estabelecidas pela escola a outros tempos sociais, alinhavando a essas relações as interações entre sujeitos no seu interior. Em outras palavras, trata-se de refletir, em torno de uma noção por demais hegemônica, o tempo como ritmo padrão, seja numa perspectiva conceitual ou de prática social. A perspectiva aqui assumida é de que o tempo escolar, como um complexus ${ }^{2}$, comporta fios de diferentes tipos que, juntos, compõem o seu tecido. A soma dos conhecimentos sobre cada um desses tipos de fio não é suficiente para compreender o tempo escolar, entendido como relação entre os tempos sociais e as temporalidades dos sujeitos.

O tempo objetivo parece ter encoberto os modos como os tempos sociais se constituem e se relacionam e como cada sujeito, na sua relação com os outros, se apropria desses diferentes tempos sociais. No dizer de Martins (2000, p. 165):

[...] a sociedade atual não é constituída de uma temporalidade única. O contemporâneo é a contemporaneidade dos tempos históricos, das vivências desencontradas porque situadas diferencialmente no percurso da história. A sociedade contemporânea se desenvolve em ritmos desiguais.

A partir da afirmação do autor, é possível admitir que, apesar do intento moderno de submeter as temporalidades de todos a uma lógica temporal hegemônica, baseada na imposição de um tempo único, a sociedade contemporânea se apresenta como um mosaico de temporalidades, que se encontram e desencontram nas relações estabelecidas entre os sujeitos em diferentes contextos sociais e situações de que participam.

As discussões presentes aqui são fruto da realização de pesquisa (Pinho, 2012; Souza, 2010) em duas escolas, a Escola Municipal de Botelho e a Escola Municipal de Praia Grande, ambas localizadas nas comunidades que lhes dão nome e situadas na Ilha de Maré - Salvador-BA. Foram realizadas 19 visitas à Ilha de Maré durante todo o ano de 2011, assim distribuídas: uma visita para conhecimento e definição do campo empírico, 11 visitas à Escola Municipal de Botelho e 7 visitas à Escola Municipal de Praia Grande. Ressalta-se que as visitas iniciais constituíram-se como primeiras aproximações com os sujeitos da pesquisa. Assim, o maior número de visitas à Escola Municipal de Botelho não significou um maior número de entrevistas. Cada professora foi entrevistada pelo menos duas vezes, e os sujeitos das duas comunidades, uma. Essa situação foi comum às duas escolas. A pesquisa contou com a colaboração de quatro professoras em cada uma das escolas, todas elas residentes na própria comunidade em que atuam. Quanto aos demais colaboradores, a pesquisa contou com a participação de seis membros

1184 Educação \& Realidade, Porto Alegre, v. 42, n. 3, p. 1183-1204, jul./set. 2017. 
das comunidades, sendo quatro da localidade de Botelho e dois de Praia Grande.

A metodologia adotada foi a narrativa (auto)biográfica, e a técnica de pesquisa selecionada foi a entrevista narrativa. Inicialmente, a intenção era realizar a pesquisa apenas com as professoras das duas escolas selecionadas. Acreditava-se que isso seria suficiente para atingir os objetivos da pesquisa. No entanto, estas, ao narrarem suas experiências pessoais, remetiam-se a outros espaços e grupos sociais, diferentes da escola. A maré, por exemplo, era recorrente em suas narrativas, o que sugeriu a necessidade de inclusão de outras vozes3: pescadores, marisqueiras e sujeitos das comunidades. Surgiam, assim, os primeiros indícios de que, para compreender o tempo escolar, era preciso levar em conta outros tempos sociais.

As entrevistas narrativas com as professoras ${ }^{4}$ foram desenvolvidas a partir da temática experiência de sala de aula, enfatizando a organização das atividades escolares. Solicitou-se que, no início, elas se apresentassem e contassem o seu percurso de formação e experiência docente. Foram informadas ainda de que, durante as entrevistas, não haveria interrupção com perguntas, que elas deveriam narrar livremente e que, só no final, quando decidissem interromper, caso fosse necessário, seriam feitas algumas perguntas a partir do que já havia sido narrado.

Os membros das comunidades que passaram a integrar a pesquisa foram indicados pelas próprias professoras, a partir do critério de sua importância e sua representatividade na comunidade. Essas entrevistas foram realizadas, de modo geral, na residência do entrevistado, com exceção de uma, que ocorreu no saguão do terminal marítimo de Botelho, local de trabalho do entrevistado. Os mesmos procedimentos descritos anteriormente foram adotados nessas entrevistas. No entanto, o estranhamento em relação à falta de perguntas foi ainda maior, gerando muitas vezes silêncios e pausas.

O uso de narrativas (auto)biográficas foi muito pertinente para a pesquisa realizada, uma vez que ela é produzida por um sujeito social que, ao contar suas experiências de vida, "[...] faz referências a diversas pertenças sociais, a uma variedade de instituições: família, escola, trabalho, amigos, bairro de sua moradia, associações" (Rhéaume, 2009, p. 167). Ou seja, essa narrativa se constitui como uma forma de expressão que é, simultaneamente, pessoal e social.

\section{A Constituição do Tempo Moderno}

A noção de tempo acompanha o ser humano ao longo da sua trajetória de vida. Na nossa cultura, desde que nascemos, lidamos com ideias como: regularidades, ritmos, simultaneidades, continuidades, descontinuidades, ordenações, seriações, durações, enfim, com construções temporais que servem de orientação para realizarmos uma multiplicidade de atividades sociais, que se transformam em sistemas de referência no processo de apropriação do tempo pelos sujeitos. 
A explicação das diferentes formas de representação, organização e valorização do tempo, depende das relações que se estabelecem entre o tempo e as diversas atividades sociais produzidas (Sue, 1995). Para esse autor, o tempo não é uma evidência, tampouco se produz por si só, pois é o produto das atividades sociais que permite medir a sua duração, seu ritmo e sua coordenação. Os grandes tempos sociais são compostos pelos tempos do trabalho, da escola, da família e do tempo livre. Ao tratar da origem do controle do tempo, Foucault (1987) assinala que a definição de horário foi herdada das comunidades monásticas, e que estas propuseram um modelo estrito de tempo, cuja difusão se deu rapidamente. Essa configuração temporal logo foi identificada nos colégios, nas oficinas e nos hospitais, pois "durante séculos, as ordens religiosas foram mestras de disciplinas: eram os especialistas do tempo, grandes técnicos do ritmo e das atividades regulares [...]" (Foucault, 1987, p. 128).

Na modernidade, produzir-se a si mesmo significou movimentar-se em meio a um tempo espacializado dos cronômetros e relógios (Matos, 2008). A representação visível do tempo, através do relógio, transformou-se no próprio tempo ${ }^{5}$. Este artefato social induziu uma verdadeira revolução na autorregulação das atividades humanas e na própria organização social, na medida em que “[...] o relógio introduz um tempo linear, abstrato, diferente dos ritmos cíclicos, cósmicos e biológicos, diferente também do tempo social, o qual é variável conforme os acontecimentos e os grupos [...]" (Petitat, 1994, p. 91). O tempo da modernidade foi conhecido e reconhecido como o único tempo possível, um tempo inventado, domesticado, usurpado, ordenado, traduzido e governado a partir das metáforas temporais da repetição, da constância, do linear, do circular (Skliar, 2003). No entanto, é fundamental o reconhecimento de que o tempo forjado na modernidade não é único, tampouco o mais praticado no interior dos grupos sociais.

Ao estudar os ritmos ocultos, Zerubavel (1985) reconheceu que a primeira característica da moderna máquina de civilização foi a sua regularidade temporal, expressa na forma de rígidas estruturas sequenciais, fixas durações, com localizações temporais uniformes e padronizadas. Além das características apontadas pelo autor, o tempo institucional moderno, de modo geral, caracterizou-se como um tempo abstrato, arbitrário, hegemônico, homogêneo, objetivo, enfim, um tempo impessoal, comandado pelos ponteiros do relógio, que passou a orientar a ocupação do tempo no trabalho, na escola, na família, nas atividades livres e de lazer, entre outras. Desse modo, a lógica temporal forjada na modernidade,

[...] quer que tudo entre num molde preestabelecido, desbastando ou acrescentando, conforme as necessidades da causa, sem verdadeira preocupação com o homem vivo, que sofre, que é feliz, que tem emoções e sentimentos, e do qual, em suma, nada se aprende etiquetando-o de um modo ou de outro [...] (Maffesoli, 1998, p. 31). 


\title{
O Tempo Escolar e os Outros Tempos Sociais
}

Essa disposição moderna foi assumida pela escola como um dos seus ideais, constituindo-se como uma instituição disciplinar, assim como os hospitais e as prisões. Não é à toa que Giddens (2009, p. 159) afirma que:

\begin{abstract}
As escolas modernas são organizações disciplinares, e seus traços burocráticos claramente influenciam e são influenciados pelas regiões que elas contêm. Como todas as formas de organização disciplinar, elas funcionam dentro de fronteiras fechadas, estando seus limites físicos claramente separados da interação cotidiana que se desenrola do lado de fora [...] a natureza fechada da vida escolar possibilita uma estrita coordenação dos encontros seriais em que os escolares estão envolvidos [...].
\end{abstract}

Será, por isso, que a escola tem dificuldade de lidar com outros tempos sociais, além do seu? É por acaso a insatisfação, a resistência dos alunos em aceitar o ordenamento temporal da escola? A afirmação do autor aponta a ânsia de fechamento das fronteiras da escola em relação ao seu entorno, a partir da tentativa de negação da vida que corre do lado de fora, fazendo com que o tempo consumido pelas crianças, em seu interior, esteja, ao menos intencionalmente, espacial e temporalmente isolado, no que se refere aos outros tempos sociais. A organização temporal da escola parece contrastar nitidamente com a dos demais setores da vida social, em que a regulação é mais solta: "[...] Como todas as organizações disciplinares, as escolas operam uma economia precisa de tempo" (Giddens, 2009, p. 159).

O modo fechado como a escola atua e sua aparente separação entre tempo e espaço - o que acontece em locais circunjacentes - inibem o controle que advém do seu exterior, como se ela constituísse um mundo à parte. É subjacente ao poder disciplinar que o que se passa no âmago do poder da escola possui um grau significativo de autonomia, que não admite interferências externas. A escola, desde o século XVIII, passou a se constituir como um lugar fechado aos olhares exteriores e, poderíamos dizer, heterônomo. Ao mesmo tempo, transformou-se num lugar que tornou possível escolarizar as atividades profissionais e religiosas, assumindo, como uma de suas principais características, a submissão às regras impessoais e a despersonalização das relações sociais (Vicent; Lahire; Thin, 2001). Com isso, a escola tentou controlar as influências do tempo subjacentes às outras atividades sociais, transformando-se num tempo específico, arbitrário, hegemônico e distanciado do tempo vivido, haja vista que o relógio e o calendário passaram a se impor, cada vez mais, como pontos únicos de referência da vida cotidiana (St-Jarre, 2001). Como diz Arroyo (2011), a escola, ao se fechar numa experiência temporal única, parece ter desconsiderado a possibilidade de outras experiências temporais vividas por diferentes sujeitos.

Apesar da intenção moderna de enquadramento do tempo, é importante considerar que a experiência temporal, concretamente vivida, 
é constituída de um caleidoscópio de tempos e temporalidades que se encontram e desencontram, formando um complexo de relações em permanente negociação. Como já havia afirmado Elias (1998, p. 47), o “[...] 'tempo' constitui uma rede de relações, amiúde muito complexa [...]"; no dizer de Pomian (1984, p. 354), isso pode significar que "existe uma pluralidade de tempos [...]" (tradução livre). Por isso, concordo com Santos (2008, p. 109), quando afirma que a vida social:

\section{[...] é constituída por uma constelação de diferentes tem- pos e temporalidades, alguns modernos outros não mo- dernos, alguns antigos outros recentes, alguns lentos ou- tros rápidos, os quais são ativados de modo diferente em diferentes contextos ou situações [...].}

Assim, compreender determinado tempo social, a exemplo do tempo escolar, pressupõe o reconhecimento e a consideração da dinâmica de outros tempos sociais, observando as características de cada um desses tempos e os modos como se dão as relações entre eles na vida cotidiana. A influência desses tempos sociais parece ser muito mais forte e poderosa do que o tempo escolar pode admitir. Nesse sentido, concordamos com Arroyo (2011, p. 310), quando afirma que "diante de vivências tão diversas que os mestres e educandos levam para as escolas, não temos o direito a impor uma única concepção do tempo".

Esses diferentes tempos sociais, segundo St-Jarre (2001), são escalonados em uma estrutura hierárquica, a partir da qual um tempo social passa a ser mais dominante que outro. No caso específico deste trabalho, a intenção não é considerar a predominância de um tempo sobre o outro, como objeto de preocupação. Ainda que se tenha percebido o aparente destaque do tempo da maré em relação aos outros, consideramos que, mais importante do que determinar qual tempo predomina nas escolas, será reconhecer que o tempo escolar se configura a partir de uma multiplicidade de tempos, sendo permeável em relação aos demais tempos sociais.

Qualquer que seja o tempo social considerado, o que está em jogo é a convivência de uma pluralidade de tempos em coordenação ou oposição entre eles. Nessa perspectiva, "[...] o tempo é um emaranhado de tempo. O tempo é um labirinto de tempo. O tempo é um redemoinho de tempo. O tempo é uma variação de tempo. O tempo é uma alucinação de tempo" (Skliar, 2012, p. 126). Isso significa dizer que o tempo escolar é constituído por um mosaico de tempos e temporalidades, não podendo ser reduzido a um ritmo padrão em que todos os outros tempos sociais e temporalidades devam ser submetidos. Como sinaliza Nóvoa (2001, p. 167):

Estamos colocados perante uma nova concepção que nos convida a olhar para a largura e para a espessura do tempo. Uma largura que permite a fluidez histórica, concebendo o presente não como um 'período' mas como um processo de transformação do passado no futuro (e vice-versa). Uma espessura que nos faz viver, simultaneamente, diferentes temporalidades, sobrepostas de tal maneira 
que o tempo deixa de ser um 'fio' (o fio do tempo) para se representar como uma corda onde muitos fios estão torcidos uns sobre os outros.

Em outras palavras, o tempo escolar, como uma corda, é constituído do entrelaçamento de diferentes tempos sociais e temporalidades que o constituem. Os sujeitos que integram a comunidade escolar são representantes legítimos dos modos como esses tempos e essas temporalidades são forjados na construção da vida cotidiana, não havendo uma hierarquia que coloca uma concepção em posição superior a outra. O que está em cheque na sociedade contemporânea é a necessidade de fazer dialogar com essas diferentes concepções sempre que os tempos vivenciados pelos sujeitos tenham que ser considerados na relação de uns com os outros, como é o caso do tempo escolar.

\section{Os Sujeitos e o Tempo Escolar}

Se, olhando para os tempos sociais, que correm do lado de fora da escola, já é possível notar o emaranhado de interações aí estabelecidas, quando se toma o interior da escola como referência, essa complexidade se aprofunda, porque inclui nessa rede de relações as temporalidades dos diferentes sujeitos, que, ao mesmo tempo em que apresentam características dos diferentes tempos sociais, exprimem modos singulares de se apropriar e experienciar o tempo. Essas formas de apropriação, no entanto, contrastam, muitas vezes, com o tempo uniformizador da escola.

Vale a pena recorrer à história para entender melhor a natureza dos conflitos em torno do tempo que se processa no interior da escola. Ela teve que inventar, ao longo da sua existência, muitos mecanismos, os mais sofisticados, para fazer com que os alunos internalizassem uma cultura temporal universal, abstrata e disciplinadora.

Nóvoa (1991) identifica duas fases significativas no processo de escolarização das crianças. A primeira, a partir do século XVI, em que a escola pertencia ao domínio da Igreja, e a segunda, a partir do século XVIII, em que a escola passou a ser de responsabilidade do Estado, vinculação que perdura até os dias atuais. Entre os séculos XVI e XVIII assistiu-se à transição do papel educativo, que antes cabia às comunidades e às famílias, para a instituição escolar. Nessa transição, o Estado assume a posição da Igreja, e ocorre um processo de institucionalização e de estatização de sistemas escolares que tendem a se transformar numa estratégia de formação para todos os níveis e categorias sociais (Nóvoa, 1991). Com efeito, esse período pode ser considerado o nascedouro da escola, como instituição, e o pensamento de Comenius, no século XVII, a base da pedagogia moderna. Com a intenção de ensinar tudo a todos, na sua Didática Magna, Comenius (2002, p. 160) advertiu que:

I. Todas as matérias de estudo devem ser divididas em aulas, de tal modo que as primeiras sempre aplanem e iluminem o caminho das seguintes; 
II. O tempo deve ser bem distribuído para que, a cada ano, mês, dia, hora, seja atribuída uma tarefa particular;

III. A medida do tempo e dos trabalhos deve ser rigidamente observada, para que nada seja esquecido ou invertido.

As afirmações revelam as marcas profundas da lógica temporal moderna nas formas de organização do tempo escolar, expressas a partir: (a) da divisão do tempo das aulas, obedecendo a uma sequência linear e gradual; (b) da distribuição precisa do tempo escolar, ao longo do ano, do mês, do dia e das horas; e (c) da observação e do controle rígidos do tempo, em uma ordem temporal preestabelecida. Nesse contexto, ensinar corresponde à utilização de mecanismos de controle do tempo, sendo o método o principal deles. A atividade docente foi reduzida à aplicação de uma técnica capaz de administrar o tempo, as coisas e o método, de maneira eficiente. O tempo assumido pela escola, ao se tornar objetivo, padronizado e exterior aos sujeitos, serve de parâmetro para agrupar e diferenciar os alunos, sequenciar as atividades escolares e uniformizar os materiais didáticos. $\mathrm{O}$ aproveitamento rigoroso do tempo significa sincronizar aprendizagens e estabelecer durações específicas e contínuas; fragmentar o processo em fases, graduando as atividades, segundo níveis de dificuldades; e tratar todos a partir do ideal de aluno médio.

O método simultâneo representou uma mudança no que se refere à organização temporal da escola. A própria ideia de simultaneidade remete à concepção de tempo, em que atividades iguais são desenvolvidas por um coletivo, que, ao ser constituído, apaga os sujeitos concretos que o compõem, a partir da idealização de um aluno médio, como se todos estabelecessem uma mesma relação com o tempo escolar. Com esse modelo de organização escolar, os professores, para garantir o atendimento sincronizado a todos os alunos, dirigem-se a eles como se fossem um só, tratando a classe como uma soma de indivíduos. Com isso, a escola adota, como referência, um aluno abstrato e idealizado, um aluno médio, cuja existência imaginária nega os alunos concretos que estão diante dos professores. Isso faz com que o alvo do ensino não seja um aluno em particular, chamado pelo nome, mas um estudante fictício, constituído por uma entidade chamada classe, que se transformou num coletivo.

A Escola Nova, em contraposição à escola tradicional, tece uma crítica aos processos de seleção baseados nos exames realizados em classes uniformes, tendo como parâmetro a ideia de aluno médio e propõe, assim, uma escola para todos, que considere as diferenças individuais. Apesar de a Escola Nova defender uma pedagogia que dê atenção à diversidade, o que se constata, na prática, é a tentativa de homogeneização das classes com base em critérios exteriores aos alunos. Ou seja: se, por um lado, a Escola Nova avança quando critica o aluno médio, por outro, incorre numa contradição explícita, porque cria, não um aluno médio, mas vários, já que, no fundo, o que se deseja é regular a heterogeneidade existente. Os alunos médios criados pela Escola Nova levam em 
consideração o reconhecimento da individualidade e a sua relação com os níveis de inteligência que são estabelecidos, segundo diferentes velocidades de resposta para a aprendizagem, separando os alunos mais rápidos dos mais lentos. O modelo proposto introduz uma relação entre tempo e diversidade, a partir de critérios reducionistas, com a intenção de racionalizar os processos educativos e garantir a uniformidade da marcha escolar. Essa Pedagogia reconhece que a escola é composta por uma diversidade de inteligências. Tal diversidade se traduz, em termos de tempo, em diferentes velocidades de aprendizagem. Assim, constata-se a redução da diversidade à inteligência e do tempo à velocidade. $\mathrm{O}$ significado da classificação dos alunos, nesse contexto de emergência da modernidade na educação brasileira, pode ser interpretado de acordo com as palavras de Skliar (2003, p. 45), quando afirma que:

As conclusões, já conhecidas, sobre a relação entre modernidade, educação e escola são evidentes: o tempo da modernidade e o tempo da escolarização insistem em ser, como decalques, temporalidades que só desejam a ordem, que teimam em classificar, em produzir mesmices homogêneas, íntegras, sem fissuras, a salvo de toda contaminação do outro.

Os critérios de classificação, com vistas à homogeneização, defendidos pela Escola Nova, baseiam-se na impossibilidade de coexistência de duas coisas diferentes, num mesmo espaço, ao mesmo tempo. Assim,

\begin{abstract}
Modernidade e escolaridade, onde duas coisas distintas não podem estar ao mesmo tempo no mesmo lugar. $\mathrm{O}$ mesmo e o outro não podem, nessa temporalidade, nessa escola, estar ao mesmo tempo. A mesmice da escola proíbe a diferença do outro (Skliar, 2003, p. 46).
\end{abstract}

Tudo isso remete à impossibilidade de reunir alunos com ritmos diferentes na mesma classe, o que gera a preocupação com a homogeneização. Se, com o aluno médio, a escola tradicional submetia todos ao mesmo ritmo, na Escola Nova, o tempo se fragmenta em quantos tipos de alunos existirem, consequentemente, em quantos forem os ritmos. Na Escola Nova, o ritmo adquiriu um grau de sofisticação, de harmonia e de equilíbrio aparentes, por conta da necessidade de internalização pelos indivíduos de mecanismos de autocontrole. Apesar da diferença entre a Pedagogia Tradicional e a Escola Nova, uma ideia se mantém: o tempo como ritmo. Na primeira, nega-se a existência concreta de diferentes ritmos em favor de uma concepção abstrata de ritmo médio, este que é usado para orientar a organização temporal e as práticas pedagógicas na escola. Ao contrário, a Escola Nova critica a ideia de ritmo médio, por seu caráter abstrato e inventado, em favor do reconhecimento dos mais diferentes ritmos concretos. Desse modo, o ritmo, que é comum às duas visões, parece ser uma propriedade biológica imanente, portanto, ao indivíduo.

A questão do ritmo sempre foi uma preocupação desde a constituição do tempo escolar. No caso da Pedagogia Tradicional, a hete- 
Fios que Tecem o Tempo Escolar

rogeneidade de ritmos foi enfrentada com a criação do ritmo médio, a fim de que todos os alunos pudessem, supostamente, acompanhar ou se adaptar ao tempo da escola. Já na Escola Nova, a heterogeneidade foi enfrentada a partir dos processos de classificação e homogeneização dos alunos, numa mesma classe, de modo que o tempo da escola se aproximasse dos ritmos dos indivíduos. Desse modo, o ritmo é comum às duas pedagogias, mas tratado de forma diferente. No primeiro caso, é o aluno que se adapta ao ritmo médio da escola. No segundo, é a escola que tenta de adequar aos ritmos dos indivíduos. Nas duas formas de organização temporal, a existência ou a necessidade de um ritmo não foi questionada, pelo contrário, foi naturalizada pela escola. Se, numa concepção biologizante do mundo, a presença do ritmo era normal e, nos fenômenos da natureza, ele também era constatado, por que na escola seria diferente? Vale dizer, que, nesse período, as ciências sociais estavam em franca expansão e tinham como referência as ciências da natureza.

Essa concepção de tempo como ritmo coloca algumas questões importantes para se pensar o tempo escolar: a crítica ao aluno médio é suficiente para compreender os problemas do tempo escolar? Classificar os alunos e agrupá-los em classes homogêneas, como fez a Escola Nova, parece não ter sido uma boa resposta. Contudo, qualquer que seja a resposta, uma questão que carece de enfrentamento é a própria ideia de tempo como ritmo.

Segundo Elias (1993), o que caracteriza o processo civilizador no Ocidente é principalmente o grau elevado de divisões de funções, interdependência e competição, atingido tanto em termos de espaço físico, quanto em termos de número de pessoas envolvidas. Alcançando um nível jamais visto na história mundial, essa interdependência engloba não apenas os oceanos, mas também se estende às terras mais distantes. Em nossa opinião, a posição de Elias (1993) contribui ainda mais para o questionamento do tempo como ritmo. O ritmo, como uma construção social moderna do Ocidente, surgiu em decorrência da rede de interdependência entre ações e processos sociais e pressupõe a sincronização dos movimentos dos indivíduos, o que implicou a necessidade de maior controle sobre o tempo.

Como parte do processo civilizador, o ritmo baseado no tempo do relógio cumpriu uma função econômica e cultural. De um lado, era preciso regular o tempo das práticas sociais e, de outro, fazer com que os indivíduos internalizassem esse ritmo. O ritmo, apoiado no relógio, insere a ideia de tempo linear, abstrato, diferente dos ritmos cíclicos, cósmicos e biológicos. Assim, constitui-se como uma tentativa de imposição, diante dos outros tempos sociais, que são variáveis nos diferentes grupos. A escola, enquanto instituição moderna, vai contribuir para que essa noção de tempo, como ritmo, seja disseminada e internalizada pelos indivíduos. Esses processos de ritmação não ocorreram sem conflito, pelo contrário, estes precisam ser valorizados e explorados quanto aos seus múltiplos significados. Levar adiante essa tarefa pode contribuir para desnaturalizar uma ideia de tempo tão cara à escola.

1192 Educação \& Realidade, Porto Alegre, v. 42, n. 3, p. 1183-1204, jul./set. 2017. 
Outra noção relacionada a tempo presente nas pedagogias analisadas é a de simultaneidade, ou seja, garantir que um professor ensine a muitos alunos, a um só tempo. Na primeira pedagogia, não é necessário que todos os alunos tenham um mesmo ritmo, porque a organização do ensino se baseia na ideia de um ritmo só, o médio, criado pela escola, o qual os alunos precisam se esforçar para acompanhar. Na segunda, muito pelo contrário, só é possível um ensino simultâneo, desde que os alunos tenham, eles mesmos, um só ritmo. É como se fosse possível fazer com que o ritmo do tempo escolar pudesse coincidir com o(s) ritmo(s) dos indivíduos. Para a Escola Nova, é uma perda de tempo inventar um ritmo médio que não tem correspondência nos indivíduos concretos.

Diante desse paradoxo que constitui o tempo escolar, vale a pena levantar algumas questões: que relação pode ser estabelecida entre ritmo e simultaneidade? Que concepção de simultaneidade está na base dessas duas pedagogias? Não será, a simultaneidade, um conceito tão problemático quanto o de ritmo? O problema está na simultaneidade ou na forma como ela foi concebida por essas pedagogias?

De nossa parte, em resumo, tentaremos sustentar a ideia de que, para fazer avançar a compreensão que a escola tem de simultaneidade, é preciso superar a ideia de tempo como ritmo. Essa afirmação ganha consistência quando se leva em consideração o diálogo que estabelecemos com as discussões teóricas sobre o tempo e as narrativas dos sujeitos participantes da pesquisa. Se, por um lado, o ritmo não se constitui em um problema nas narrativas de pescadores e sujeitos das comunidades, na sua relação com o tempo, por outro lado, aparece de forma recorrente nas narrativas das professoras, o que o torna um problema na relação dos sujeitos com o tempo escolar.

Nas escolas pesquisadas, a relação do tempo escolar com os outros tempos sociais é tensa, criativa e contraditória. Na relação com os outros tempos, algumas vezes, a escola se rende, procurando observar como eles regulam a vida na comunidade e, outras vezes, ela tenta impor a sua lógica temporal para organizar o seu próprio tempo. O mesmo parece acontecer quando observamos as relações que ocorrem no seu interior, isto é, apesar de tentar impor o seu tempo aos sujeitos, como se quisesse tornar os movimentos dos alunos idênticos, deixa escapar a possibilidade de interação entre diferentes temporalidades.

\section{O Tempo como Ritmo}

A ideia de ritmo associada a tempo de aprendizagem aparece de forma recorrente nas narrativas das professoras. O Outro é concebido como aquele que possui um ritmo, e este constitui um problema ao se relacionar com outros ritmos, principalmente os do tempo escolar. É comum a professora propor uma atividade, e nem todos conseguirem acompanhar no ritmo idealizado por ela, que parece se situar no intervalo entre um ritmo rápido e outro lento: um ritmo médio. 
Fios que Tecem o Tempo Escolar

Era de se esperar que o ritmo rápido fosse o ideal, mas as professoras constatam que, muitas vezes, o aluno que acaba a atividade antecipadamente termina atrapalhando os outros. Já os alunos com ritmo lento, não deixam que a professora avance nas atividades. Nesse contexto, fica difícil uma sincronização. Além disso, o ritmo do aluno nem sempre corresponde a critérios objetivos, como série ou idade.

Em outras palavras, a concepção de ritmo parece estar ligada ao tempo próprio de um indivíduo e exprime um desenvolvimento biológico específico. O ritmo, enquanto tempo de aprendizagem, geralmente aparece associado à velocidade, que pode ser mais ou menos lenta ou rápida. Ele pode ser quantificado, é mensurável. Uma turma torna-se problemática para as professoras, à medida que os alunos tenham diferentes ritmos, numa escala que vai do muito lento ao muito rápido.

O parâmetro para essa classificação é o ritmo próprio do tempo escolar, que deve ser acompanhado pelos sujeitos. Mas as professoras se veem diante de um problema: adequar os ritmos dos sujeitos ao ritmo do tempo escolar. Diante disso, não há muito o que fazer, senão tentar ampliar o tempo para os alunos considerados mais lentos - solução apontada por Freitas (2003, p. 19-20) como uma possível saída. Segundo o autor, "caso se queira unificar os desempenhos (nível elevado de domínio para todos), há que se diversificar o tempo de aprendizagem. Para tal, é preciso permitir que cada um avance a seu ritmo usando todo o tempo que lhe seja necessário”. O problema desse tipo de sugestão é que ela dá margem a se pensar o tempo do sujeito como uma propriedade individual, um ritmo, o que pode reforçar o isolamento, e não a interação, no processo de aprendizagem.

Deixando de lado as tentativas de enfrentamento do problema, vale a pena valorizar as dificuldades das professoras em conciliar os ritmos dos sujeitos ao da escola. Por que as dificuldades dessa conciliação? Tem ela a ver com a própria noção de ritmo enquanto expressão do tempo? Quais as implicações dessa concepção objetiva de tempo para os sujeitos das práticas educativas, professor e aluno?

A nós interessa desnaturalizar a ideia de ritmo padrão, questionando-a como forma de representação do tempo. Aproveitando as palavras de Sacristán (2005, p. 11), cabe desconfiar daquilo que nos parece familiar e que:

[...] tende a ser visto como natural; quando isso ocorre naturalizamos o que nos rodeia, os contatos e as relações que mantemos com o que nos cerca, como se sua existência fosse resultado da espontaneidade, como se sempre tivesse existido e, inevitavelmente, tivesse de existir. Esse modo de ser penetra em nossas vidas, dá sentido ao modo de entendermos e de nos representarmos no mundo cotidiano, isto é, dá conteúdo a nosso senso comum.

Sacristán refere-se à naturalização da condição de aluno. Aqui, queremos nos referir à naturalização do ritmo como propriedade do tempo. Como questionar aquilo que é condição da existência do tempo? Parece ser prudente apostar na diferença entre o dado e o representado.

1194 Educação \& Realidade, Porto Alegre, v. 42, n. 3, p. 1183-1204, jul./set. 2017. 
Para Askin (1969, p. 174), “o ritmo é que serve para exprimir a repetição em desenvolvimento" e é entendido como o elemento da forma temporal de ser da matéria em movimento. Esta noção tem, segundo ele, importância singular para a ciência moderna, nos seus processos de investigação da natureza inerte e da natureza viva, uma vez que estas são constituídas por seus processos rítmicos. $\mathrm{O}$ ritmo vinculado à perspectiva espacial pode, também, aparecer como expressão de certa repetição de elementos que existem simultaneamente. Nesse sentido, o conceito de ritmo assume uma importância singular, no que se refere ao tempo, uma vez que torna possível a definição do ritmo como um conceito temporal. Os processos de desenvolvimento são constituídos pela dinâmica do ritmo, sua principal característica. De modo geral, a regularidade, entendida como alternância uniforme de determinados elementos, é identificada com o conceito de caráter rítmico. Assim, a permanência dos processos da natureza, sua estabilidade relativa e sua regularidade, é caracterizada pelo ritmo, que "[...] é a expressão de um determinado tipo de enlace de elementos no aspecto temporal" (Askin, 1969, p. 178).

Geralmente, o que caracteriza a integridade de um sistema é o tempo. De modo mais preciso, em comparação com outras propriedades temporais, é o ritmo que garante a integridade de um sistema: "O ritmo único aparece como característica que forma uma unidade de funcionamento e, por conseguinte, a existência de um sistema como fator de integridade" (Askin, 1969, p. 179). Nesse sentido, tomando a escola como um sistema, o que está em jogo, quando se diz que o tempo escolar é ritmo? É a sua integridade? É a sua integridade que prevalece em detrimento da suposta existência de outros ritmos? Como é possível manter a unidade na diversidade, considerando a pluralidade de temporalidades, no interior da escola, e os tempos sociais que o atravessam? Sem a pretensão de responder a essas perguntas, partimos das crenças das professoras, sobre o que pode ser o ritmo. Elas nos dão uma pista importante por onde começar a problematizá-lo: a relação com o outro.

Em Bakhtin (2003), o ritmo adquire um sentido específico, diferente de Askin (1969). De fato, segundo Faraco (2010, p. 20), no discurso teórico do autor russo, essa noção se distancia das descrições de uso comum. Em outras palavras:

O ritmo, entendido como uma realidade temporal, ocorrência de uma repetição ordenada, (a intervalos regulares) de um fenômeno, de uma atividade, de uma duração sonora (o ritmo do coração, das marés, da música, da prosa ou da poesia) perde, em Bakhtin, seu sentido descritivo (fenomênico) e incorpora um valor, uma carga axiológica. Ritmo é entendido como um ordenamento axiológico, uma modelagem, uma enformação da vida.

Trata-se de um ordenamento que apresenta a vida vivida ou a vivência, não como algo experienciado pelo outro, pelo próprio vivenciador, mas como realidade dada, fechada, consumada. Como se quisesse superar o futuro, tal como ele é, indeterminado, imprevisível, arriscado. 
O ritmo é, assim, um imperativo. Ele tenta impor uma vida ritmada ao outro.

Chama a atenção a ideia de enformação da vida relacionada à noção de ritmo. Aplicando essa ideia às relações humanas, enformar parece significar controle e regulação sobre o tempo dos outros. Dar uma forma é submeter o tempo do outro ao tempo do mesmo. Bakhtin (2003), quando trata da enformação, se refere ao campo da literatura, assim, o autor-criador "[...] subordina a personagem a uma existência ritmada para alcançar a transposição da vida para o plano estético" (Faraco, 2010, p. 22). Mas aqui estamos falando de educação. É possível, então, estabelecer analogias? Acreditamos que sim, pois a educação, pelo menos a moderna, como já disse Dubet (2006), pode ser concebida como um "trabalho sobre os outros", ainda que articule socialização e subjetivação. Da mesma forma que o autor-criador busca adequar a personagem a uma vida ritmada, para atingir a transposição da existência para a dimensão estética, a educação pode desejar subordinar o outro a uma existência ritmada, objetivando a transposição do real vivido para o plano estético-educacional.

Aprofundando a ideia de ritmo, em Bakhtin, Faraco (2010) argumenta que a vida do outro concreto é, essencialmente, organizada e definida no tempo. O outro, apreendido de fora, é instalado integralmente no tempo. As fronteiras temporais em que a vida do outro é delimitada, a tornam vulnerável a um tipo de acabamento, liberto do futuro, mensurável e ritmado. O ritmo, pela sua regularidade e previsibilidade, fecha, modela, enforma, predetermina.

O ritmo é um beijo e um abraço no tempo axiologicamente adensado da vida mortal do outro. Onde há ritmo, há duas almas (mas exatamente, alma e espírito), há dois ativismos; a vida que vivencia e a que se tornou passiva para a outra, que a enforma e celebra ativamente [...]. Às vezes me alieno justificada e axiologicamente de mim mesmo, vivo no outro e para o outro, e então posso me incorporar ao ritmo, mas nele sou eticamente passivo para mim (Bakhtin, 2003, p. 110).

O ritmo é incompatível tanto com o livre-arbítrio como com o ativismo, em certas condições, ainda que submetido:

Onde quer que eu esteja, no entanto, sou sempre livre. Não posso fugir ao imperativo da liberdade e, para exercê-la (ou seja, para assumir a responsabilidade pelos meus atos - no sentido amplamente discutido em Para uma filosofia do ato responsável), é preciso suspender o ritmo, desalienar-me, desanestesiar-me (Faraco, 2010, p. 22).

Se a utilização da expressão "sou sempre livre” incomoda, por possibilitar a ideia de um voluntarismo subjetivista, não é nesse sentido que se está falando. Concordo, não apenas com Bakhtin (2003), mas também com Charlot (2000, p. 41), quando afirma que "todo ser humano é um sujeito, inclusive quando dominado e alienado [...]”.

1196 Educação \& Realidade, Porto Alegre, v. 42, n. 3, p. 1183-1204, jul./set. 2017. 
Na condição de sujeito, o aluno pode reagir a sua incorporação ao ritmo e à tentativa de revestimento da carne axiológica do outro (costumes, modos de vida, nacionalidade, religião, dentre outros). Nesse sentido, reagir ao ritmo, imposição do tempo do outro, parece significar muito mais que a reação a uma simples tentativa de subordinação a uma velocidade, mas corresponde a um enfrentamento das visões de mundo alheias às suas. Pode significar, também, como diria Faraco (2010), referindo-se a Bakhtin (2003), uma contraposição ao mundo racionalizado, reduzido ao cálculo, previsível e ritmado.

Diante disso, ir à festa, brincar na maré, ou ser lento podem ser interpretados como a expressão do não ritmo, da manifestação do ativismo, do livre-arbítrio. Mostrar-se lento aos olhos do outro pode significar uma resistência ao ritmo, como ordenamento temporal que tenta abolir "[...] as possibilidades em aberto do acontecimento, seu traçado em devir [...]" (Faraco, 2010, p. 20).

Sendo assim, como abrir mão da noção de tempo enquanto ritmo, sem abrir mão da educação enquanto acabamento estético, em que os educadores têm a possibilidade de enriquecer a vida dos seus alunos pelo excedente de visão estética, dado o lugar que cada um ocupa no mundo? Em outras palavras, que outra concepção de tempo escolar é possível, levando em consideração os tempos sociais e as temporalidades dos sujeitos?

$\mathrm{O}$ acontecimento parece estranho à mensuração e à previsibilidade do ritmo. Isto é, a abertura do acontecimento, sua indeterminação absoluta, seu contorno em devir, o arriscado desfecho do acontecimento na vida vivida coloca em xeque o ritmo como expressão do tempo. Com isso, mais que uma descrição de intervalos regulares, o ritmo corresponde ao valor atribuído ao fenômeno temporal. Diante disso, que outra concepção de tempo assumir, para pensar o tempo escolar?

\section{O Desafio da Simultaneidade: o tempo e o Outro}

Apesar de o ritmo ser a noção mais comum nas narrativas das professoras, a ideia de simultaneidade marca presença, constituindo-se como uma alternativa de concepção de tempo escolar, mais especificamente no que se refere ao tempo de aprendizagem. Em alguns momentos, a simultaneidade aparece como um paradoxo, em outros, como uma possibilidade. No primeiro caso, a simultaneidade entre os diferentes cria uma situação que surpreende a professora, já que alunos considerados menos adiantados conseguem, na interação com seus pares, alcançá-los ou até ultrapassá-los em níveis de conhecimento.

Afinal que é a simultaneidade do ponto de vista do tempo? Que relação existe entre tempo, diferença e outro? A simultaneidade pode ser pensada como uma superação da ideia de ritmo padrão? Uma vez aceita como expressão temporal, a simultaneidade é aplicável ao contexto da educação?

Segundo Clark e Holquist (1998), tanto Einstein quanto Bakhtin passaram o resto de suas vidas tentando desvendar um conceito por

Educação \& Realidade, Porto Alegre, v. 42, n. 3, p. 1183-1204, jul./set. 2017.1197 
demais indefinido - o de simultaneidade. A primeira comunicação de Einstein, datada de 1905, defende que toda crença acerca do tempo objetivo de um dado evento é, em verdade, uma afirmação "[...] sobre a ocorrência simultânea de dois eventos, o evento em questão e, digamos, a superposição dos ponteiros de um relógio sobre os números pintados num mostrador" (Clark; Holquist, 1998, p. 94). Por exemplo, quando Einstein afirma que o trem chegou em determinado horário à estação, ele está se referindo, na realidade, a acontecimentos simultâneos. Para o físico, a simultaneidade não aparece, geralmente, como um problema, já que, na vida ordinária, "[...] há um encaixe enganadoramente próximo entre os eventos nos mostradores de nossos relógios e os que sucedem no mundo" (Clark; Holquist, 1998, p. 94). Chega a afirmar que a simultaneidade efetiva não existe. Com isso, o autor parece referir-se à impossibilidade de ocorrência de dois eventos, rigorosamente iguais, do ponto de vista do tempo. O que há é apenas sistemas de referência através dos quais dois eventos distintos podem ser dirigidos a uma unidade conceitual.

Bakhtin (2010), buscando fazer para a consciência o mesmo que Einstein tentava fazer, na mesma época, em relação ao universo físico, argumenta que o sistema de referência que gera esse efeito de simultaneidade se encontrava numa espécie de mecânica das transformações do self/outro, particularmente, numa espécie de princípio da localização. Tentando traduzir este princípio ou essa lei da localização, como afirmam Clark e Holquist (1998), o sítio particular de onde eu vejo as coisas é governado pelo lugar de onde eu as vejo. A isso Bakhtin chamou de exotopia; em outras palavras:

[...] você pode ver coisas às minhas costas, como uma pintura ou nuvens que passam, mas estão ocultas à minha visão, enquanto eu posso ver coisas das quais você, de sua localização, não tem visão, como uma pintura diferente em outra parede ou outras nuvens que se movem por trás de sua cabeça. Esta diferença determina que, embora estejamos no mesmo evento ele é diferente para um e para outro (Clark; Holquist, 1998, p. 95).

A outridade, a não coincidência, é assim uma marca constitutiva da percepção humana. Do lugar único ocupado por mim na existência há coisas que somente eu posso ver: a porção de mundo que apenas a mim é possível notar é, na verdade, um excedente de visão estética, um excedente do meu ver, em que esse excedente é pautado "[...] em relação à falta que todos os outros têm daquele mundo moldado exclusivamente por mim" (Clark; Holquist, 1998, p. 96). Mas é importante evitar qualquer mal-entendido em relação a esse excesso, já que ele perde o significado, sempre que não se refere a outros.

Então, as ideias de Bakhtin confirmam a hipótese de Einstein de que, no fundo, não há simultaneidade? A preocupação com a outridade enquanto condição humana insere Bakhtin (2010) numa tradição filosófica moderna que tem, na diferença, um importante objeto de reflexão, mas o que o distancia dessa tradição é a possibilidade de contemplar 
diferenças na simultaneidade. É aqui que talvez ele se distancie do que disse Einstein. Sobre o modo como se dá essa simultaneidade na outridade, Bakhtin (2010) dá importantes pistas, quando analisa a poética de Dostoiévski. Segundo ele, a categoria central em Dostoiévski não é formação, mas coexistência e interação. Mas as contradições e seus desdobramentos presentes nessas interações entre consciências não se tornam dialéticas, porque não são colocadas na dinâmica de via temporal, num processo de formação, mas se desenrolam "[...] em um plano como contíguos e contrários, consoantes mas imiscíveis ou como irremediavelmente contraditórios, como harmonia eterna de vozes imiscíveis ou como discussão interminável e insolúvel entre elas" (Bakhtin, 2010, p. 34). Que concepção de tempo alimenta essa preocupação de Bakhtin (2010) com a dialogação entre as diferenças? Esta é uma pergunta difícil de responder, porque exige uma incursão mais demorada em sua obra, tendo em vista que este autor, apesar de ter dado importância ao tempo, não sistematizou tal conceito em sua obra. Como já visto, Bakhtin (2010) fundou a sua noção de tempo na simultaneidade, o que pressupõe o encontro com o outro. Assim, nos arriscamos a especular que tempo, em Bakhtin, é acontecimento, abertura ao devir, indeterminação, possibilidade. As advertências de Bachelard (2007) nos aproximam de alguns autores que colocam, no centro do debate, o tempo e a relação com o outro. Começamos por aquele que, na nossa percepção, assumiu o outro como condição da existência do tempo, sendo uma referência importante para os estudiosos dessa questão. Referimo-nos a Levinas (2011a; 2011b). Além disso, este se inspira no próprio Bachelard (2007), para pensar o tempo enquanto instante. Na tessitura do pensamento de Levinas, o tempo é concebido como acontecimento, configura-se como descontinuidade, em que cada instante é um novo começo, um nascer de novo. O tempo acrescenta algo de novo ao ser, algo de absolutamente novo (Levinas, 2011a, p. 281). O tempo é essencialmente nascer de novo (Levinas, 2011b). Pode-se dizer assim, que o tempo é diacrônico e significa tempo heterogêneo, não linear e descontínuo. Cada instante, ao incorporar a alteridade, produz um acontecimento inédito. Com isso, a descontinuidade dos instantes impede a determinação histórica do Mesmo. O tempo diacrônico é a possibilidade da reinvenção constante do mundo. Como bem destaca Mauer (2007), a irrupção do Outro, da diferença, é o que faz do tempo uma realidade. Tempo e diferença em Levinas (2011a; 2011b) são inseparáveis. O sentido do tempo do Outro consiste em não pertencer ao tempo do Mesmo e não ser ordenado segundo a sua lógica. "Os tempos do Mesmo não esclarecem o tempo do Outro" (Souza, 2004, p. 176). "É este o sentido do tempo do outro para além de toda crono-logia, oferecendo-se ao encontro que é a construção do sentido" (2004, p. 178). Além disso, essa relação com o outro homem é uma "[...] relação sem mediação, face a face" (Santos, 2009, p. 115). A gênese do tempo reside no outro-homem, o que faz com que o tempo seja entendido como espaçamento.

A relação com a alteridade, é que provoca a transcendência do tempo. "Somente o Outro em sentido eminente - não somente outro eu, mas outro que o eu - pode propiciar a transcendência para além do 
império mundano do sujeito [...]" (Santos, 2009, p. 256). A representação do Outro, como signo, diferencia-se da sua presença. Essa distância aponta a necessidade de partir da presença que ele difere para só então reconhecê-lo. Derrida (1991) aponta o caráter provisório do signo e argumenta em favor de não mais compreendermos a diferença como signo ou representação de uma presença. A diferença assim é concebida por ele, como aquilo que faz com que o movimento da significação não seja possível, a não ser que cada elemento, dito presente, estabeleça uma relação com outra coisa que não seja ele mesmo. O Outro para Levinas é pensado "[...] como um outro concreto, de carne e osso, que tem um rosto que o diferencia, que se volta para mim como eu me volto para ele, e que é suscetível de sofrimento" (Canalli, 2006, p. 139). O tempo do eu que guarda outrem, nasce da fecundidade desse eu. "A relação com o filho, ou seja, a relação com o Outro, não poder, mas fecundidade, põe em relação com o futuro absoluto ou o tempo infinito" (Levinas, 2011a, p. 267). Tal fecundidade consiste na possibilidade de um sujeito se fazer outro e, por intermédio desse quase si mesmo, que é o filho, tornar a abrir o tempo às possibilidades inexpressas do eu. "Para Levinas a fecundidade propicia nada menos que a 'ressurreição' do tempo do sujeito [...]" (Santos, 2009, p. 140).

Tempo, nessa perspectiva, é, então, encontro, enquanto disposição "[...] ao ainda não conhecido" (Souza, 2008, p. 176). Significa dizer que o eu assume um lugar que pode ser questionado, "[...] em uma situação de insegurança, pelo mero aparecer da alteridade e isto porque desde o Outro não provém nenhuma promessa de conciliação, mas a constatação traumática do fato de que a totalidade de minhas concepções é incapaz de lhe fazer justiça” (2008, p. 176-177). O Outro não está diante de mim como objeto, chega até a minha presença e "[...] permanece Outro frente as capacidades do meu poder representacional, um acontecimento traumático - ainda que tal não seja primariamente percebido desta forma" (2008, p. 177). Levinas (2011b) defende que o encontro com o outro distingue-se da mera exposição mútua de dois sujeitos numa correlação. A origem da temporalidade na relação entre o Mesmo e o Outro, estabelece-se nas dimensões do diálogo e da filiação. Ademais, longe de ser uma fusão, a relação com o outro é sobretudo uma relação. A relação com o outro não é assim idílica e harmoniosa, relação de comunhão, nem uma simpatia. Nós a reconhecemos sensível a nós, mas exterior a nós. A relação com o outro é uma relação com o mistério (Levinas, 2011b).

As reflexões feitas até aqui apontam, a nosso ver, para outra concepção de tempo, enquanto simultaneidade, que pressupõe não a imposição, mas o encontro com o outro, baseado na coexistência e na interação. Este estudo aponta a simultaneidade como uma possibilidade do tempo, em que a relação ética com o outro é condição para as práticas educativas. Vale ressaltar que essa relação ética com o outro pressupõe o seu reconhecimento, não como representação, mas como diferença, como irrupção do Outro, aquele que emerge de maneira intempestiva, imprevisível. Isso significa o enfrentamento do reconhecimento dis-

1200 Educação \& Realidade, Porto Alegre, v. 42, n. 3, p. 1183-1204, jul./set. 2017. 
torcido do outro, lento, lerdo, atrasado, indisciplinado, desinteressado, desatento, com idade avançada, que tem problema em acompanhar o tempo escolar. Enfim, essa racionalidade ética coloca em xeque a ideia de tempo como ritmo, como aquele que quer se impor aos outros tempos sociais e às temporalidades dos sujeitos. Olhando para o interior da escola, para um tipo específico de relação pedagógica, a concepção de tempo, enquanto ritmo, é problemática, pois insistir nessa ideia é impor um tempo que nega a condição de sujeito do Outro. E assim, o tempo escolar, das duas escolas pesquisadas, é convidado a reconhecer a existência e a legitimidade de outros tempos, para além do seu, seja o tempo da maré, o tempo do trabalho, o tempo das práticas simbólicas, o tempo livre e as temporalidades dos sujeitos.

Recebido em 16 de dezembro de 2015 Aprovado em 17 de março de 2017

\section{Notas}

1 O presente texto apresenta resultados da Tese de Pinho (2012), com financiamento da CAPES, sob orientação de Elizeu Clementino de Souza, vinculada ao projeto Diversas Ruralidades - Ruralidades Diversas: sujeitos, instituições e práticas pedagógica em escolas rurais da Bahia-Brasil, financiado pela Fundação de Amparo à Pesquisa do Estado da Bahia (FAPESB) e do Conselho Nacional de Desenvolvimento Científico e Tecnológico (CNPq).

2 Complexus, termo latino que significa o que é tecido junto.

3 No caso dos pescadores, marisqueiras e outros membros das comunidades, foram utilizados seus próprios nomes ou apelidos, antecedidos pela forma abreviada do pronome de tratamento, no caso em questão Sr. e Sra.

4 Apesar de as professoras terem autorizado o uso de suas narrativas para o desenvolvimento da pesquisa, os nomes são fictícios, a fim de preservar as suas identidades. Os nomes adotados foram sugeridos pelas próprias professoras e serão antecedidos pela forma abreviada profa., a fim de distingui-las dos demais participantes da pesquisa.

5 No entanto, para Elias (1998, p. 15), “[...] nas sociedades avançadas, os relógios ocupam um lugar eletivo dentre os dispositivos destinados a representar o tempo, mas não são o tempo".

\section{Referências}

ARROYO, Miguel. Currículo, Território em Disputa. Petrópolis: Vozes, 2011.

ASKIN, Iakov Fomitch. O Problema do Tempo: sua interpretação filosófica. Tradução de Joel Silveira. Rio de Janeiro: Paz e Terra, 1969.

BACHELARD, Gaston. A Intuição do Instante. Tradução de Antonio de Padua Danesi. Campinas: Verus Editora, 2007.

BAKHTIN, Mikhail. Estética da Criação Verbal. Tradução de Paulo Bezerra. São Paulo: Martins Fontes, 2003.

BAKHTIN, Mikhail. Problemas da Poética de Dostoiévski. Tradução de Paulo Bezerra. Rio de Janeiro: Forense Universitária, 2010. 
Fios que Tecem o Tempo Escolar

CANALLI, Rodrigo Lobo. O guardião do meu irmão: do ser-aí ao ser-para-o-outro. In: MILOVIC, Miroslav; SPRANDEL, Maia; COSTA, Alexandre; NASCIMENTO, Wanderson Flor do (Org.). Sociedade e Diferença. Brasília: Casa das Musas, 2006. P. 133-143.

CHARLOT, Bernad. Da Relação com o Saber: elementos para uma teoria. Porto Alegre: Artes Médicas Sul, 2000.

CLARK, Katerina; HOLQUIST, Michael. Mikhail Bakhtin. Tradução de Pedro Jorgensen Jr. São Paulo: Perspectiva, 1998.

COMENIUS, João Amos. Didática Magna. 2. ed. São Paulo: Martins Fontes, 2002.

DERRIDA, Jacques. A diferença. In: DERRIDA, Jacques. Margens da Filosofia. Tradução de Joaquim Torres Costa e António M. Magalhães. Campinas: Papirus, 1991. P. 33-63.

DUBET, François. El Declive de la Institución: profesiones, sujetos e individuos ante la reforma del Estado. Tradução de Luciano Padilla. Barcelona: Gedisa, 2006.

ELIAS, Norbert. O Processo Civilizador. Tradução de Ruy Jungmann. v. 2. Rio de Janeiro: Jorge Zahar, 1993.

ELIAS, Norbert. Sobre o Tempo. Tradução de Vera Ribeiro. Rio de Janeiro: Jorge Zahar, 1998.

FARACO, Carlos Alberto. O Espírito não Pode Ser o Portador do Ritmo. Bakhtiniana, São Paulo, São Paulo, v. 1, n. 4, p. 17-24, 2. sem. 2010.

FOUCAULT, Michel. Vigiar e Punir: nascimento da prisão. Tradução de Raquel Ramalhete. Petrópolis: Vozes, 1987.

FREITAS, Luiz Carlos de. Ciclos, Seriação e Avaliação: confronto de lógicas. São Paulo: Moderna, 2003.

GIDDENS, Anthony. A Constituição da Sociedade. Tradução de Álvaro Cabral. São Paulo: Martins Fontes, 2009.

LEVINAS, Emmanuel. Totalidade e Infinito. Tradução de José Pinto Ribeiro. Lisboa: Edições 70, 2011a.

LEVINAS, Emmanuel. Le Temps et L'autre. Paris: Presses Universitaires de France, 2011b.

MAFFESOLI, Michel. Elogio da Razão Sensível. Tradução de Albert Christophe Migueis Stuckenbruck. Petrópolis: Vozes, 1998.

MARTINS, José de Souza. A Sociabilidade do Homem Simples: cotidiano e história na modernidade anômala. São Paulo: Hucitec, 2000.

MATOS, Olgária. Adivinhas do Tempo: êxtase e revolução. São Paulo: Hucitec, 2008.

MAUER, Manuel. Tempo, Diferença e Alteridade: Lévinas, leitor de Bergson. In: LECERF, Eric; BORBA, Siomara; KOHAN, Walter. Imagens da Imanência: escritos em memória de H. Bergson. Belo Horizonte: Autêntica, 2007. P. 209-224.

NÓVOA, Antônio. Para o Estudo Sócio-Histórico da Gênese e Desenvolvimento da Profissão Docente. Teoria e Educação, Porto Alegre, n. 4, p. 109-139, 1991.

NÓVOA, Antônio. Tempos da Escola no Espaço Portugal-Brasil-Moçambique: dez digressões sobre um programa de investigação. Currículo sem Fronteiras, Porto Alegre, v. 1, n. 2, p. 131-150, jul./dez. 2001.

PETITAT, André. Produção da Escola/Produção da Sociedade: análise sócio-histórica de alguns momentos decisivos da evolução escolar no ocidente. Tradução de Eunice Gruman. Porto Alegre: Artes Médicas, 1994.

1202 Educação \& Realidade, Porto Alegre, v. 42, n. 3, p. 1183-1204, jul./set. 2017. 
PINHO, Ana Sueli Teixeira de. O Tempo Escolar e o Encontro com o Outro: do ritmo à simultaneidade. 2012. 274 f. Tese (Doutorado em Educação e Contemporaneidade) - Programa de Pós-graduação em Educação e Contemporaneidade, Universidade do Estado da Bahia, Salvador, 2012.

POMIAN, Krzysztof. L'ordre du Temps. Paris: Éditions Gallimard, 1984.

RHÉAUME, Jacques. Relato de Vida Coletivo e Empoderamento. In: TAKEUTI, Norma Missae; NIEWIADOMSKI, Christophe (Org.). Reinvenções do Sujeito Social: teorias e práticas biográficas. Porto Alegre: Sulina, 2009. P. 166-188.

SACRISTÁN, José Gimeno. O Aluno como Invenção. Porto Alegre: Artmed, 2005. SANTOS, Boaventura de Sousa. A Gramática do Tempo: para uma nova cultura política. São Paulo: Cortez, 2008.

SANTOS, Luciano. O Sujeito Encarnado: a sensibilidade como paradigma ético em Emmanuel Levinas. Ijuí: Editora Unijuí, 2009.

SANTOS, Milton. Técnica, Espaço, Tempo: globalização e meio técnico-científico-informacional. 5. ed. São Paulo: EDUSP, 2008.

SKLIAR, Carlos. Pedagogia (Improvável) da Diferença e se o Outro não Estivesse aí?. Tradução de Giane Lessa. Rio de Janeiro: DP\&A, 2003.

SKLIAR, Carlos. Experiências com a Palavra: notas sobre linguagem e diferença. Rio de Janeiro: Wak Editora, 2012.

SOUZA, Elizeu Clementino (Org.) et.al. Ruralidades Diversas - Diversas Ruralidades: sujeitos, instituições práticas pedagógicas nas escolas do campo, Bahia/ Brasil. 2008. Relatório Técnico de Pesquisa apresentado ao Conselho Nacional de Desenvolvimento Científico e Tecnológico, no âmbito do Edital MCT/CNPq 03/2008. Salvador: Universidade do Estado da Bahia, 2010, $132 \mathrm{f}$.

SOUZA, Ricardo Tim. Em Torno à Diferença: aventuras da alteridade na complexidade da cultura contemporânea. Rio de Janeiro: Lumen Juris, 2008.

SOUZA, Ricardo Tim. Razões Plurais: itinerários da racionalidade ética no século XX: Adorno, Bergson, Derrida, Levinas, Rosenzweig. Porto Alegre: EDIPUCRS, 2004.

ST-JARRE, Carole. L'organisation du Temps en Éducation: les Cadres de Référence. In: ST-JARRE, Carole; DUPUY-WALKER, Louise. Le Temps en Éducation. Québec, Canadá: Press de L'Université du Québec, 2001. P. 15-41.

SUE, Roger. Temps et Ordre Social. Paris: Presses Universitaires de France, 1995.

VICENT, Gui; LAHIRE, Bernard; THIN, Daniel. Sobre a História e Teoria da Forma Escolar. Educação em Revista, Belo Horizonte, n. 33, p. 7-47, jun. 2001.

ZERUBAVEL, Eviatar. Hidden Rhythms: schedules and calendars in social life. Chicago; London: The University of Chicago Press, 1985. 
Ana Sueli Teixeira de Pinho é doutora em Educação e Contemporaneidade pelo Programa de Pós-Graduação em Educação e Contemporaneidade da Universidade do Estado da Bahia (PPGEduC-UNEB). Pesquisadora do GRAFHO Grupo de Pesquisa (Auto)biografia, Formação e História Oral (GRAFHO). Professora da Universidade Católica do Salvador (UCSal). Assessora Pedagógica do Instituto Anísio Teixeira - IAT. Vice-coordenadora do Projeto Multisseriação e Trabalho Docente: diferenças, cotidiano escolar e ritos de passagem (CNPq e FAPESB).

E-mail: anasuelipinho@yahoo.com.br

Elizeu Clementino de Souza é pesquisador 1C CNPq. Professor Titular do Programa de Pós-Graduação em Educação e Contemporaneidade, da Universidade do Estado da Bahia (PPGEduC-UNEB). Coordenador do GRAFHO (Grupo de Pesquisa (Auto)biografia, Formação e História Oral). Pesquisador associado do Laboratorie EXPERICE (Université de Paris 13 - Paris 8). Coordenador do Projeto Multisseriação e trabalho docente: diferenças, cotidiano escolar e ritos de passagem (CNPq e FAPESB).

E-mail: esclementino@uol.com.br 